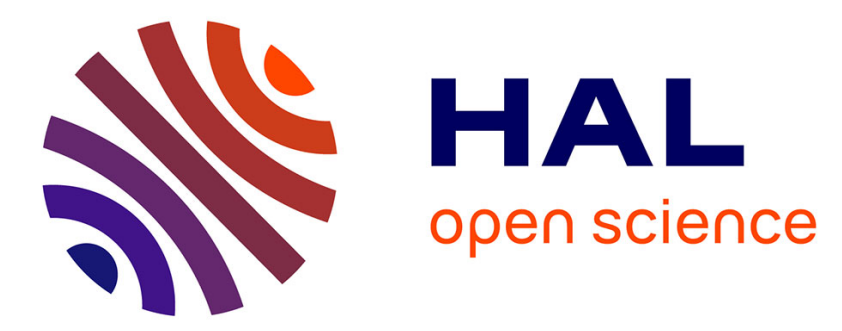

\title{
Super-elastic Behavior of Shape Memory Alloys under Proportional Cyclic Loadings
}

\author{
Luc Saint-Sulpice, Shabnam Arbab-Chirani, Sylvain Calloch
}

\section{To cite this version:}

Luc Saint-Sulpice, Shabnam Arbab-Chirani, Sylvain Calloch. Super-elastic Behavior of Shape Memory Alloys under Proportional Cyclic Loadings. Materials Science and Engineering: A, 2008, 481-482, pp.174-177. 10.1016/j.msea.2007.02.144 . hal-00449151

\section{HAL Id: hal-00449151 \\ https://hal.science/hal-00449151}

Submitted on 4 Feb 2010

HAL is a multi-disciplinary open access archive for the deposit and dissemination of scientific research documents, whether they are published or not. The documents may come from teaching and research institutions in France or abroad, or from public or private research centers.
L'archive ouverte pluridisciplinaire HAL, est destinée au dépôt et à la diffusion de documents scientifiques de niveau recherche, publiés ou non, émanant des établissements d'enseignement et de recherche français ou étrangers, des laboratoires publics ou privés. 


\title{
Super-elastic Behavior of Shape Memory Alloys under Cyclic Loading
}

\author{
Luc Saint-Sulpice*, a $^{*}$, Shabnam Arbab Chirani ${ }^{\mathrm{b}}$ and Sylvain CAlloch ${ }^{\mathrm{a}}$ \\ ${ }^{a}$ Laboratoire MSN, ENSIETA, Brest, France \\ ${ }^{\mathrm{b}}$ Laboratoire de Recherche en Mécatronique, ENIB, Brest, France
}

\begin{abstract}
This paper concerns the super-elastic behavior of Shape Memory Alloys (SMA) under cyclic loadings. Particular attention is paid to ratchetting (i.e., evolution of residual strain with the number of cycles). First, a series of uniaxial tensile tests on $\mathrm{Cu}-\mathrm{Al}-\mathrm{Be}$ wires has been presented. In a second part, a macroscopic model is proposed and identified from experimental results.
\end{abstract}

Keywords: Cu-Al-Be Shape Memory Alloys, super-elasticity, cyclic loading, ratchetting, macroscopic approach

\section{Introduction}

In many engineering applications, structures and components of SMA are subjected to cyclic loads. This can create a cumulative residual deformation (i.e., ratchetting) [1,2].

Ratchetting is an aspect of the mechanical behavior of metalic alloys that has received considerable attention over the last twenty years $[3,4]$. Among the great number of investigations, few studies concern the super-elastic behavior of SMA.

The purpose of the present work is, on one hand, to build an experimental database under uni-axial cyclic tensile loading and, on the other hand, to propose a macroscopic model taking into account the main effects of cyclic loads on the behavior of

* Corresponding author: L. Saint-Sulpice, e-mail address: saint-lu@ensieta.fr, tel: +33 (0)2 983489 41, fax: +33(0)298348730.
SMA.

\section{Experimental investigation under uni-axial cyclic tensile loading}

The material chosen for this study is a $\mathrm{Cu}-\mathrm{Al}$ Be SMA (Cu: $87 \%$, Al: 11\%, Be: 2\%, atomic percentages). The material is available as wire with a $1.4 \mathrm{~mm}$ diameter. Each wire was heat treated at $923 \mathrm{~K}$ during twenty minutes and then quenched in boiling water during one hour.

An uni-axial loading-unloading tensile test has been performed to characterize the specific behavior of our material. The tests have been performed with a Zwick electro-mechanical testing machine operating in axial strain control. A 10-mm extensometer has been used to measure the axial strain. All the tests have been performed at room temperature. 
Figure 1 shows the stress-strain curve for twentyfive loading-unloading cycles. It can be observed that for our material:

- a residual strain, $\varepsilon^{r}$, appears after the first cycle and grows with the number of cycles until a reached limit (figure 2 ),

- the maximum stress, $\sigma_{\max }$, is not influenced by the cyclic loading (figure 3 ),

- the slope at reload, $E_{r}$, decreases slightly after the first cycle (figure 4).

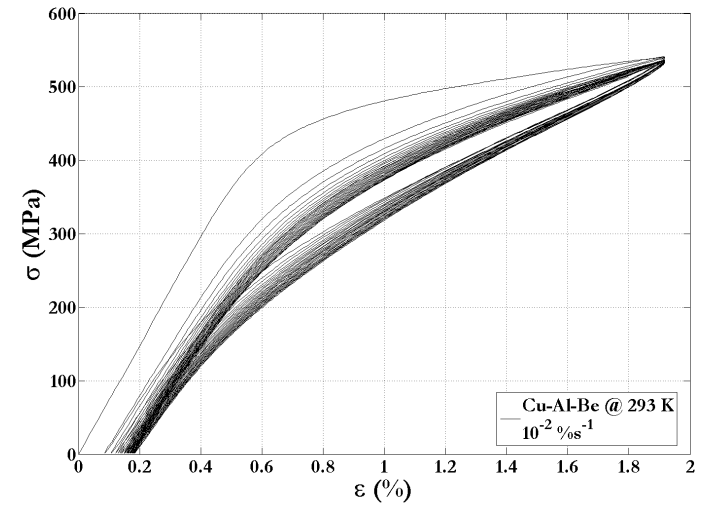

Fig. 1. Test stress-strain curves for loading-unloading cycles.

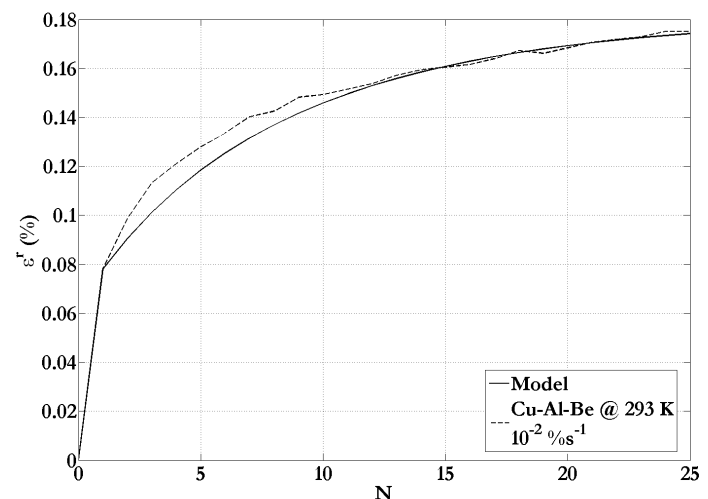

Fig. 2. Evolution according to the number of cycles of the residual strain $\varepsilon^{r}$.

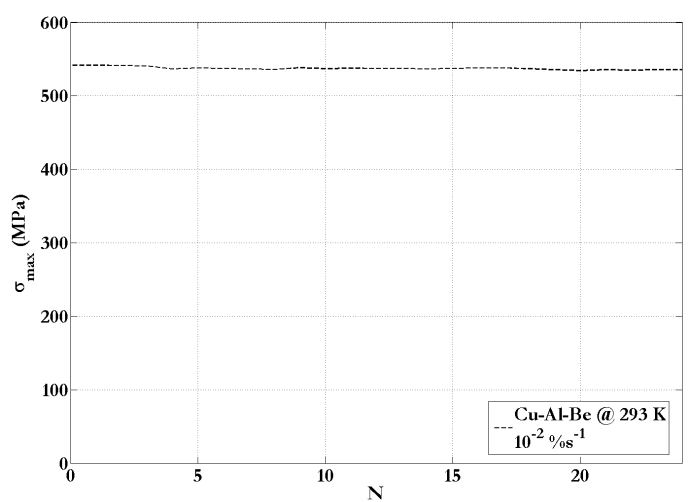

Fig. 3. Evolution according to the number of cycles of the maximum stress $\sigma_{\max }$

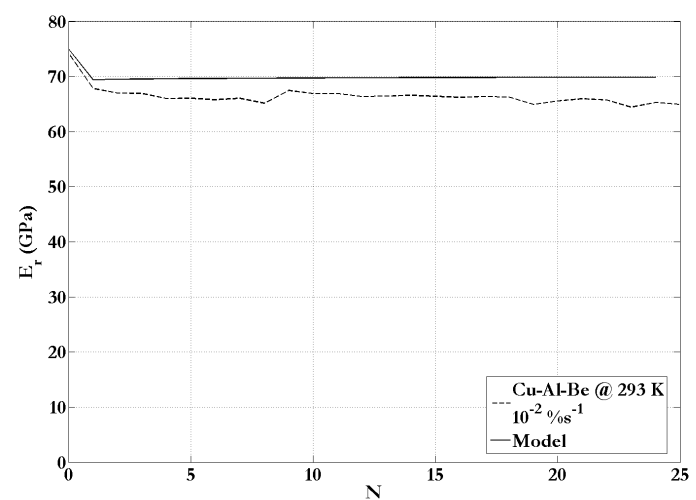

Fig. 4. Evolution according to the number of cycles of the slope at reload $E_{r}$.

\section{A cyclic super-elasticity model: one-dimensional loading case}

The proposed model is based on the superelasticity model recently proposed by Bouvet et al. [5].The main originality concerns the description of the elastic domain of the material, at a two-phased state (i.e., austenite and martensite), by two different "yield" surfaces for forward and reverse transformation, respectively. In this work, a modification is proposed to take into account the effect due to cyclic loading.

The constitutive equations of the model are presented hereafter (the interested reader can find more details in [5]): 
- Strain decomposition is:

$$
\varepsilon^{t r}=\varepsilon-\varepsilon^{e}=\varepsilon-\frac{\sigma}{E}
$$

- Relation between martensite volume fraction and transformation strain is:

$$
z=\frac{\varepsilon^{t r}}{\gamma}
$$

- "Yield" function for forward transformation is:

$$
f_{1}=\sigma-R(z)-\sigma_{0}(T) \leq 0
$$

- "Yield" function for reverse transformation is:

$$
f_{2}=-\sigma+R(z)+\sigma_{0}(T)-\delta \leq 0
$$

- "Flow" rule for forward transformation is:

$$
\varepsilon^{\dot{t} r}=\dot{\lambda_{1}} \frac{\partial f_{1}}{\partial \sigma}=\dot{\lambda_{1}}=\gamma \dot{z}
$$

- "Flow" rule for reverse transformation is:

$$
\varepsilon^{\dot{t} r}=\dot{\lambda_{2}} \frac{\partial f_{2}}{\partial \sigma}=-\dot{\lambda_{2}}=\gamma \dot{z}
$$

- Evolution of "yield" surfaces size during forward transformation is:

$$
R(z)=R_{\max } \frac{\ln \left(1+\left(n_{1}-1\right) z\right)}{\ln n_{1}}
$$

- Evolution of "yield" surfaces size during reverse transformation is:

$$
R(z)=R_{C}+f\left(\frac{z}{z_{B}}\right)\left(R_{B}-R_{C}\right)
$$

with $f(z)=z\left(1+n_{2}(1-z)^{2}\right)$,

$R_{B}=R_{\max } f\left(z_{B}\right)$ and $R_{C}=\Delta R_{m}\left(1-e^{-b z_{c}}\right)$

- Cumulated martensite volume fraction is:

$$
z_{c}=\int|\dot{z}| d t
$$

Where $E, \gamma, \sigma_{0}, \delta, R_{\max }, n_{1}, n_{2}, \Delta R_{m}$ and $b$ are material parameters.

\section{A cyclic super-elasticity model: multi-axial proportional loading case}

The proposed model is based on the previous model. The modification is to take into account the multi-axial proportional effect (figure 5).

The constitutive equations of the model are presented hereafter:

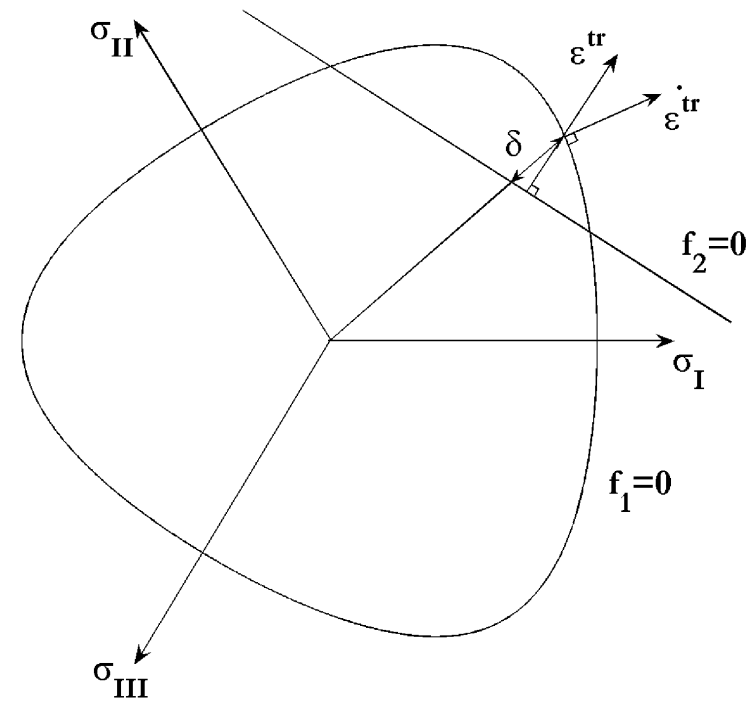

Fig. 5. Yields functions describing the behavior of shape memory alloy.

- Strain decomposition is:

$$
\mathbb{E}^{t r}=\mathbb{E}-\mathbb{E}^{e}=\mathbb{E}-\mathbb{E}^{-1} \mathbb{\mathbb { V }}
$$

- Relation between martensite volume fraction and transformation strain is:

$$
z=\frac{\varepsilon_{e q}^{t r}}{\gamma}
$$

with $\varepsilon_{e q}^{t r}=\overline{\varepsilon^{t r}} \frac{g\left(-y_{\varepsilon}\right)}{g(-1)}, \bar{\varepsilon}=\sqrt{\frac{2}{3} \varepsilon^{t r}: \varepsilon^{t r}}$,

$y_{\varepsilon}=4 \frac{\operatorname{det}\left(\varepsilon^{t r}\right)}{\overline{\varepsilon r}^{3}}$

- "Yield" function for forward transformation is:

$$
f_{1}=\mathbb{\sigma}_{e q}-R(z)-\sigma_{0}(T) \leq 0
$$

with $\mathbb{\Xi}_{e q}=\bar{\sigma} g\left(y_{\sigma}\right), \bar{\sigma}=\sqrt{\frac{3}{2} \mathbb{\mathbb { V }}: \mathbb{\sigma}}$,

$g(y)=\cos \left(\frac{\cos ^{-1}(1-a(1-y))}{3}\right)$,

$y_{\sigma}=\frac{27}{2} \frac{\operatorname{det}(\operatorname{dev}(\sigma))}{\bar{\sigma}^{3}}$

- "Yield" function for reverse transformation is:

$$
f_{2}=-\mathbb{\varpi}_{e q}+R(z)+\sigma_{0}(T)-\delta \leq 0
$$

- "Flow" rule for forward transformation is:

$$
\dot{\varepsilon}^{\dot{t} r}=\dot{\lambda_{1}} \frac{\partial f_{1}}{\partial \varpi}
$$

- "Flow" rule for reverse transformation is:

$$
\dot{\varepsilon^{t} r}=\dot{\lambda_{2}} \frac{\partial f_{2}}{\partial \mathbb{U}}
$$




\begin{tabular}{cccccccccc}
\hline$E$ & $\gamma$ & $\sigma_{0}$ & $\delta$ & $R_{\max }$ & $n_{1}$ & $n_{2}$ & $\Delta R_{m}$ & $b$ & $a$ \\
\hline $75 \mathrm{GPa}$ & $5.85 \%$ & $360 \mathrm{Mpa}$ & $10 \mathrm{MPa}$ & $250 \mathrm{MPa}$ & 81.2 & 0.2 & $3.4 \mathrm{GPa}$ & 0.3 & 0.7 \\
\hline
\end{tabular}

Table 1

Material parameters for a $\mathrm{Cu}-\mathrm{Al}-\mathrm{Be} \mathrm{SMA}$ at room temperature.

- Evolution of "yield" surfaces size during forward transformation is:

$$
R(z)=R_{\max } \frac{\ln \left(1+\left(n_{1}-1\right) z\right)}{\ln n_{1}}
$$

- Evolution of "yield" surfaces size during reverse transformation is:

$$
R(z)=R_{C}+f\left(\frac{z}{z_{B}}\right)\left(R_{B}-R_{C}\right)
$$

with $f(z)=z\left(1+n_{2}(1-z)^{2}\right)$,

$R_{B}=R_{\max } f\left(z_{B}\right)$ and $R_{C}=\Delta R_{m}\left(1-e^{-b z_{c}}\right)$

- Cumulated martensite volume fraction is:

$$
z_{c}=\int|\dot{z}| d t
$$

Where $\mathbb{E}, \gamma, \sigma_{0}, \delta, R_{\max }, n_{1}, n_{2}, \Delta R_{m}, b$ and $a$ are material parameters.

\section{Material parameters identification}

The material parameters set has been identified using the experimental results presented in the second section. The parameters values obtained for our $\mathrm{Cu}-\mathrm{Al}-\mathrm{Be} \mathrm{SMA}$ are given in table 1.

Figure 6 shows the stress-strain evolution obtained by the model. It can be noted that the model takes into account accurately the main effect observed for a super-elastic behavior under loadingunloading cyclic test. Figures 2-4 show the comparison between experimental results and modeling concerning the residual strain, the maximum stress and the slope at reload evolutions, respectively. A good agreement can be observed.

\section{Conclusion}

In this work, a constitutive model has been proposed to describe the super-elastic behavior of a $\mathrm{Cu}-\mathrm{Al}-\mathrm{Be} \mathrm{SMA}$ under cyclic loadings.

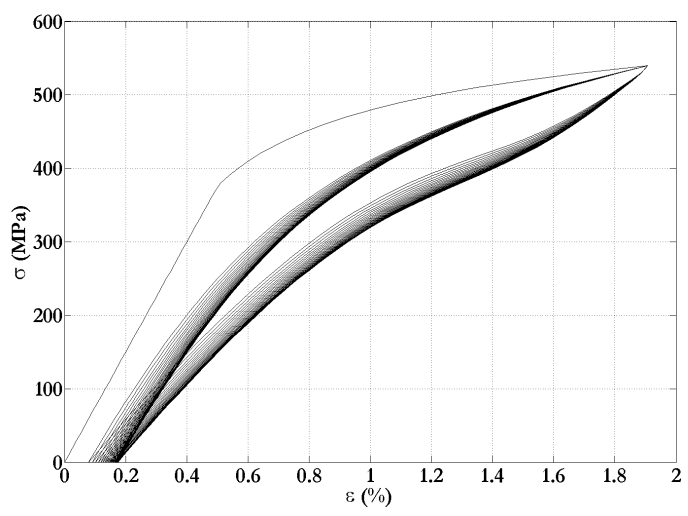

Fig. 6. Model stress-strain curves for loading-unloading cycles.

In its general version (i.e., 3D formulation), the model takes into account the super-elasticity, the tension-compression asymmetry, the return point memory effect, the martensite reorientation under non-proportional multi-axial loading and the ratcheting under cyclic loading.

\section{References}

[1] K. Gall and H.J. Maier, Cyclic deformation mechanisms in precipited NiTi shape memory alloys, Acta Materialia, Vol. 50, pp 4643-4657, 2002.

[2] H. Tobushi, P.H. Lin, T. Hattori and M. Mikata, Cyclic deformation of NiTi shape memory alloy, JSME International journal A, Vol. 38, nř1, pp 59-67, 1995.

[3] L. Vincent, S. Calloch and D. Marquis, A general cyclic plasticity model taking into account yield surface distortion for multi-axial ratchetting, Int. J. of Plasticity, 20, pp. 1817-1850, 2004.

[4] N. Ohno, Recent Progress in constitutive modeling for ratchetting, Materials Science Research International, 3(1), pp.1-9, 1997.

[5] C. Bouvet, S. Calloch and C. Lexcellent, A phenomenological model for pseudoelasticity of shape memory alloys under multiaxial proportional and nonproportional loadings, European Journal of Mechanics A/Solids, Vol. 23, pp. 37-61, 2004. 